\title{
Foresight-Technology Transformation for Textile Industry Future Assessment
}

\author{
R.S. Ibragimova ${ }^{1, *}$ and D.S. Golovkin ${ }^{2}$ \\ "Corresponding author: irozalia@ hotmail.com \\ ${ }^{1}$ Ivanovo State University, Ivanovo, Russia
}

\begin{abstract}
This article deals with the problem of improving the tools of long-term planning for industries sustainable development in a turbulent environment and in accordance with the challenges of the fourth industrial revolution. The main objective of the study is to create the strategic management methods, providing the economic potential growth and competitiveness in global markets. The authors propose a methodological approach to assessing the economic potential of the textile industry, based on the integration of the economic potential concept and Foresight-technologies. The Foresight study vectors are selected for the formation a holistic image of the desired future and for determination ways to achieve it. For each vector, a set of tools was proposed according to such key research criteria as expertise, creativity, interaction, evidence. Strategic directions for textile industry development in modern conditions were determined on the basis of Foresight studies.
\end{abstract}

Keywords: economic potential, innovative growth, Foresight, textile industry, management efficiency.

\section{Introduction}

The relevance of the research lies in the fact that an integrated approach to the industry economic potential management allows to make timely and strategically appropriate management decisions that ensure the growth and competitiveness in global markets, taking into account the risks and opportunities for sustainable development. At the same time, new approaches to research are required to determine successful areas of activity and strategic directions for companies' development. Such approaches include Foresight. The importance of foresight studies for the textile industry in Russia is growing due to the need for fundamental changes in the industry reconstruction and the restructuring the technical base in accordance with new challenges and threats to the world market.

\section{Problem Statement}

To determine the strategic directions for improving the competitiveness, efficiency and sustainability of enterprises in any industry it is require an integrated predictive assessment of the future, which would take into account the current situation of the enterprise, its competence and opportunities in the global environment. We believe that such an assessment can be obtained on the basis of the use the category "enterprise economic potential" [1].

Assessment of economic potential and formation the company's growth strategy are inextricably linked with the anticipation of its future position, formed under the influence of global trends. In this regard, methodological approaches not only to the analysis of possible scenarios of the company's development, but also to the definition of ways to "approach" to the desired situation in the future play an important role in solving the problems of choosing the priority directions for the growth of economic potential. The basis for such an approach development may be Foresight $[2,3,4,5]$. The essence of the Foresight concept as a methodology for choosing the future path of innovative development actualizes its application to solve the problems of economic potential management of any industry, as Foresight-technology provides a more comprehensive approach than traditional methods of long-term planning and forecasting. It should be noted that this aspect of Foresight application is not given due attention in the economic literature.

\section{Research Questions}

In the process of the research, we studied how the economic potential concept and Foresight can be integrated to develop methodological and methodical approaches to the strategic management of textile companies in the modern global environment. In addition, we were interested in what are the key areas of the textile industry development that would ensure the economic potential growth and competitiveness in world markets 


\section{Purpose of the Study}

The purpose of our research is to improve approaches to enterprises strategic management on the basis of integration the economic potential concept and Foresight, and also transformation and adaptation Foresight-technology to solve actual problems of textile industry development. The specific objectives of the study are:

- clarification the essence of the categories "enterprise economic potential", "foresight technology", "innovation cluster");

- adaptation the foresight-method for the purposes of economic potential management of textile industry enterprise;

- assessment the technological state of the textile industry in Russia;

- identification the possible ways to make a breakthrough in the development of the textile industry.

\section{Research Methods}

In the research, economic phenomena were investigated from the standpoint of the theory of systems. We used the methods of exploratory and descriptive studies such as literature review, case-study, trends analysis, benchmarking, expert interviews, workshops, brainstorming and others.

\section{Findings}

The scientific novelty of our methodological approach to the textile industry management is the integration of the economic potential concept and foresight within the strategic management system of industrial enterprises. The proposed approach makes it possible to timely determine successful areas of activity and development directions, to make strategically appropriate management decisions that ensure the growth of competitiveness in global markets, taking into account the risks and opportunities for sustainable growth.

In the context of the proposed approach, the content of its main categories "enterprise economic potential" and "foresight" is clarified. The economic potential of the enterprise is interpreted as the enterprise ability to ensure its longterm functioning, development and achievement strategic goals through the use of available resources, taking into account the opportunities and the accumulated competencies in order to satisfy the consumer individual demand in goods and services. This interpretation of the category allows to present the relationship between resources and opportunities at each stage of the capital cycle and thus cover the entire financial and economic cycle of the organization, as well as to assess the strategic directions for socio-economic and innovative development of the enterprise.

"Foresight" is considered as a system of methods for assessing the strategic directions of innovative development and for identifying technological breakthroughs that can have a significant impact on the economy of enterprises and industries in the medium and long term.

Developing a methodology for the textile industry potential management based on foresight studies, we took into account the complexity of strategic goals. We considered the industrial enterprises potential as a system of interrelated elements, the main components of which are the scientific and technical base, technology and production, marketing, logistics, finance, personnel, organization and management. In accordance with these elements of economic potential, we proposed to allocate the following vectors of foresight studies for textile enterprises in order to form a holistic image of the desired future and to determine ways to achieve it:

Vector 1. Industry scientific achievements. Innovative materials and products. New product design, engineering and design tools.

Vector 2. Breakthrough technologies in textile production.

Vector 3. Global trends in the industry market. New needs, trends in consumer behavior under the influence of digital transformation of economic sectors. New tools and methods in marketing.

Vector 4. The future of logistics systems and technologies.

Vector 5. New competencies and knowledge. The future of professional education. Social environment of enterprises.

Vector 6. Progressive business models, organizational and management systems, management tools. The business internationalization models. Trends in cluster development of the industry.

Vector 7. Effective financial models.

Vector 8. A holistic image of the textile industry future.

On the basis of the integration the concept of economic potential and foresight in the study, it was developed a methodical approach to the assessment of strategic directions for the textile industry, which takes into account the industry specifics, the above vectors of foresight studies to form a holistic image of the industry desired future, as well as the advantages and limitations of foresight technologies. The process of foresight research includes the following stages:

At the first stage, within the framework of a specific foresight vector, it is necessary to formulate the problem, to specify the subject of research, to set a goal and objectives. This stage is preliminary, in which the following steps are of great 
importance: review of literature on the study problem; collection and statistical data analysis; the opinions analysis of recognized representatives in this field; public opinion analysis (forums, social networks, etc.).

The second stage of the study is to select specific foresight technologies and techniques for solving the tasks formulated at the first stage, basing on four key criteria [5]:

- expertise is provided by the use of Delphi methods, expert panels, expert interviews, studies of industry associations to identify opinions on trends in the subject area;

- creativity is based on such elements of creative analysis as science fiction, scenario method, role-playing games, critical technologies, road maps;

- interaction is carried out by involving as many representatives of science, business, government, education, the public in the study as possible on the basis of seminars, voting, surveys, brainstorming;

- evidence is based on literature review, modeling, extrapolation, benchmarking.

Within the framework of separate vectors of the foresight project, we presented a set of methods and tools that should be used in a complex for the successful implementation of all four key research factors: expertise, creativity, interaction, evidence.

The third stage is actually holding a foresight session using the selected technologies. Any foresight technology involves mapping the future, identifying trends, options and alternatives. Field studies, such as consumer surveys, are also carried out at this stage.

The final stage of the foresight session is the preparation of results that can be presented in the form of roadmaps, i.e. documents reflecting the possible ways of company (industry) development in the future, on the basis of which long-term strategic priorities in the studied areas are formed. This is the basis for the realization of a desired future. Road maps are formed for each of the key vectors, as well as in general. They set the trajectory from the current state of the industry and its links to the desired future position in the global space.

So, the proposed approach to strategic management based on the integration of the concept of economic potential and foresight provides a comprehensive solution to the problems of fundamental structural changes in the industry in accordance with the challenges of the global environment, forms the basis for the transition the industry to a qualitatively new stage of development.

Within each of the foresight vectors outlined above, from the perspective of long-run growth theories $[6,7,8,9]$, the tendencies of textile industry development in the context of globalization of economic processes and challenges of the fourth industrial revolution have been investigated. It is revealed that due to the lack of investment in technological innovations over a long period of time, the technological gap between Russian manufacturers and the companies of leading countries-players in the global textile market is only increasing and becoming critical. The necessity of using endogenous models of economic growth, based on investments in knowledge and new technologies, to avoid the industry crisis and to make breakthrough has been substantiated. On the basis of benchmarking and statistical analysis, it is concluded that to ensure the textile industry revival in Russia and to overcome the technological gap requires a significant increase in investment in advanced technologies and innovations, the creation the factories of the future, innovative platforms and clusters, ensuring the interaction of all participants in the process of innovation and technological growth of the industry.

P. Romer's endogenous models (1986) [7] explain how growth can occur through technology transfer and organizational innovation between different sectors of the economy. The country's economy is growing, because companies in some sectors are leaders for companies in other sectors, the diffusion of advanced technologies provides a stable dynamics of development. Creation the innovative products in the textile industry is based on inter-sectoral cooperation with the chemical industry, IT sector, engineering, materials science, etc. The use of advanced technologies in various sectors and the creation the innovative products contribute to the integrated development, to the opening of new areas of product use and long-run growth of the industry efficiency.

In the global textile industry, innovation is primarily associated with new product applications, such as light composite materials for construction, "smart textiles" for medicine, functional fabrics for workwear, materials for the aerospace industry, composite materials containing textile fibers for solar panels, flexible materials for pipeline transport, customized "smart clothes", etc. A noticeable trend in the global market is the growth acceleration in the production of high-tech technical textiles, which are more than 1.5 times faster than traditional textiles. Currently, the share of technical textiles in the total world output is about $40-50 \%$.

At present, there are real cases of diffusion the modern advanced technologies in textile production, which can be the basis for the creation factories of the future. It is possible to distinguish the following already existing technologies in the field of digital transformation the textile and clothing industry: robotic technologies in garment enterprises; digital design and modeling of textiles and garments; 3D printing of nonwovens and clothing; digital printing in finishing production; intelligent sensors in production lines and "smart" materials; automation and integration of production and management processes; predictive Analytics and Big Data technology for customization of textile and clothing products; machine learning and CRM systems for customer relationship management; e-Commerce, etc.

As a result of analysis of situation in science and available research resources, we came to the conclusion that in the current conditions the most acceptable competitive strategy of technological and innovative development for the Russian industry is the strategy of dynamic catch-up, which provides for the active adaptation and implementation the best world achievements in the field of research and development, as well as the government coordination the research activities of domestic organizations and companies. In Russia, there are all prerequisites for the implementation of this strategy in the textile industry: the presence of stable research schools and centers, as well as the emergence of large 
companies interested in the introduction the innovations and expansion the competitive products in foreign markets (for example, the Corporation "Nordtex", Unistyle Holding, the company "Faberlik", LLC "Association of enterprises "TDL", JSC "Shuisky Chintz", JSC "Mega", etc.).

In our study, special attention is paid to the role of the state in creating favorable conditions for socio-economic development, and especially in the field of investment support. In addition, in the information age, companies operate on the basis of integrated business processes, so the government must constantly ensure the interaction of all participants in the process of innovation and technological growth of the industry, as well as the infrastructure development, including clusters and technology platforms.

Within the sixth vector of foresight "Progressive business models, organizational and management systems, management tools" the concept of clustering the regional economy has been analyzed. We consider the innovation cluster as a management mechanism that ensures the formation the effective business models of a certain specialization on the basis of systematic interaction of all participants in the process of creating a value chain from research and development to the implementation and consumption an innovative product. As a result of the study, we identified the key factors that form the conditions for the functioning of cluster formations and contribute to the success in the implementation of the cluster strategy: 1) the optimal state financial motivation system, 2) the existence of a developed support infrastructure, 3) the deep development of the scientific and educational sector, close and active interaction between universities, research institutes and industrial companies, 4) the development of venture organizations, 5) reliance on the existing competitive technological potential of local industrial enterprises and scientific organizations, 6) the existence of leading enterprises, able to lead innovation processes and consolidate around the rest of the organizations, 7) the presence of highly qualified specialists of the world level, 8) the presence in the cluster of small businesses, 9) the presence of a network for the information exchange between small and medium-sized innovative enterprises, educational and research institutions, 10) the establishment of procedures for the careful selection of companies before entering the cluster, 11) the interest of the local community in the cluster creation. The interest of stakeholders (businesses, scientific and educational sector, investors, partners, regional and Federal authorities) in the application of the cluster strategy was evaluated.

In the framework of the seventh foresight vector "Effective financial models" we have developed an approach to the economic potential management of the textile industry based on the integration of the economic potential concept and balanced scorecard. Scientific novelty of our research is the author's technique of building a BSC for the purposes of assessing the economic potential of the textile industry enterprises, which features are 1) introduction to BSC indicator "enterprise value, $\mathrm{EV}$ " as a generalized quantitative characteristics, reflecting the level of enterprise economic potential; 2) accounting in the BSC formation following factors: stage of the industry life cycle, trends in the country's economy development, competitive conditions and the current stage of business life cycle.

\section{Conclusion}

Currently, foresight technologies are used to solve various management problems. The paper presents methodological approach to the assessment of strategic directions for innovative development of the textile industry based on the integration of the economic potential concept and foresight technologies, which takes into account the industry specifics, vectors of foresight studies selected on elements of enterprise economic potential, to form a holistic image of the desired industry future.

To ensure the textile industry revival in Russia and overcome the technological gap requires a significant increase in investment in advanced technologies and innovations, the creation of factories of the future, innovative platforms and clusters that ensure the interaction of all participants in the process of innovation and technological growth of the industry, as well as large-scale support from the state.

\section{Acknowledgements}

The study was carried out with the financial support of RFFR, project № 18-410-370004 "Forecasting and evaluation of strategic directions for socio-economic and innovative development of the textile industry on the basis of foresight studies».

\section{References}

1. R. Ibragimova, D. Golovkin, Methodological substation of the estimation of economic potential of the enterprise. Modern High Technologies. Regional Application, 3(47), 64-74 (2016). [in Rus.].

2. P. Becker, Corporate foresight in Europe: A first overview. Luxembourg: Office for Official Publications of the European Communities (2003).

3. D. Loveridge, Foresight - seven paradoxes. International Journal of Technology Management, 21(7-8), 781-791 (2001). 
4. B.R. Martin, Foresight in science and technology. Technology Analysis \& Strategic Management, 7(2), 139-168 (1995).

5. R. Popper, Methodology: common foresight practices \& tools. In L. Georghiou (Ed.), International Handbook on Foresight and Science Policy: Theory and Practice (pp. 123-144). Cheltenham: Edward Elgar (2007).

6. R.E. Lucas, On the mechanics of economic development. Journal of Monetary Economics, 22, 3-42 (1988).

7. P. Romer, Increasing returns and long-run growth. Journal of Political Economy, 94, 1002-1037 (1986).

8. J. Schumpeter, The theory of economic development. New Jersey: Transaction Books (1934).

9. R.M. Solow, Contribution to the theory of economic growth. The Quarterly Journal of Economics, 70(1), 65-94 (1956). 